\title{
Knowledge on Place of Delivery and Postnatal Care Among Reproductive Women in Urban Ghana: A Qualitative Thematic Synthesis
}

Jones Asafo Akowuah ( $\square$ asafojones60@gmail.com )

Kwame Nkrumah University of Science and Technology

Opuni Antwiwaa Ama

Ghana Health Service

Rita Addai

Christian Health Association of Ghana

Dina Sarpong

Ghana Health Service

\section{Research Article}

Keywords: Facility delivery, maternal health, thematic analysis, Ghana, Staff attitude, TBA, Ghana

Posted Date: July 9th, 2021

DOl: https://doi.org/10.21203/rs.3.rs-622836/v1

License: (a) (i) This work is licensed under a Creative Commons Attribution 4.0 International License. Read Full License 


\section{Abstract \\ Background}

Place of birth delivery continues to be a canker to maternal healthcare despite the introduction of interventions and policies aimed to promote maternal health. Otutcomes on the choice of place of delivery has not been captured using rigorous qualitative approaches, which are empirically proven. This study investigated the accounts of mothers who have delivered in the last five years either home, assisted by TBAs or health facilities backed by care providers during labour and delivery and to evaluate the reasons for choice of delivery in urban Ghana.

\section{Methods}

Using an in-depth interview and two focus groups conducted with women of reproductive age (15-49) who had delivered in the past five years in the study area. The study investigated women's opinions, perceptions and experiences of care in terms of factors that influenced place of delivery, satisfaction with services and whether they would recommend services to neighbours.

\section{Results}

2 out of 16 mothers delivered home assisted TBA's by despite the introduction of the free maternal delivery in addition to other available interventions such as focused ANC aimed at improving maternal healthcare.

\section{Conclusion}

The findings suggest that enabling factors to healthcare delivery are key to women's expectations, which in turn build up satisfaction. Service improvements, which address aspects of care, are likely to have an impact on health seeking behaviour and utilisation. Findings recommend that the Municipal health directorate adopt more user-friendly approaches and interventions to attract mothers who use home delivery and retain those who deliver in facilities.

\section{Introduction}

Low use of prenatal and maternal healthcare services including health facility delivery is evident as the major cause of adverse birth outcomes globally [1]. As a result, more than half a million women worldwide die each year because of complications arising from pregnancy and childbirth [2]. It is reported that Africa has the highest rates of maternal mortalities, mostly due to direct obstetric causes $(33.9 \%)$, sepsis (9.7) and hypertensive disorders (9.1) [3]. These high cases of maternal mortalities have been the major reason pregnant women are encouraged to seek for early health care services in most parts of the 
world, especially in the sub-Saharan Africa [4, 5]. Many of these deaths could be avoided through pragmatic crosscutting interventions including emergency obstetric care for women with complications and skilled delivery care. A key among these interventions aimed to controlling maternal mortalities is antenatal care (ANC).

Despite improved maternal healthcare delivery using standardised procedures and protocols, a number of pregnant women in the sub-Saharan region still deliver in places other than health facilities [6, 7]. The reasons behind these observations are varied, and demand the broad engagement of politicians, policymakers, researchers, healthcare practitioners and the lay with the view to reaching out to lasting pragmatic solutions. Hence, there is the need to put both local and scientific knowledge on equal footing, since such synergies have always proven to work (Wilcox, 2003) [8].

There have been extensive research on the influences of health facility delivery including $[6,7,9,10,11$, $12,13,14,15,16,17,18]$. Most of these studies dwell extensively in the quantitative tradition of enquiry with the exception of a very few. The study seeks to fill this grey area using qualitative approach to investigate reasons on place of delivery and postnatal care urban Ghana. The work of [16] broadly reviews the available literature using broad themes to reflect their research outcomes. The work of [15] uses in-depth interviews and focus group to investigate women's perceptions and experiences that influenced place of pregnancy delivery. The health seeking behaviours of population groups have been conceptualised by several theoretical models including $[19,20,21]$. Among the widely used theoretical models on health care use include the health belief model (HBM), trans theoretical model (TTM), theory of planned behaviour (TPB), social cognitive theory (SCT).

The current paper adapts Andersen's healthcare utilisation model, which demonstrates factors that lead to the use of health services [22]. The theory has three dimensions namely; predisposing, enabling and need (PEN) factors. Specifically, predisposing factors comprise demographic, social, structural and attitudinal (belief systems) dynamics which increase the likelihood of a person to seek for health care. Enabling factors refer to the influences that empower people's use of health care services. They include the social and community networks found within the family and society, and cut across local, national and global spectrums. Need factors indicate the actual problem of discomfort that the patient experiences and the severity of this condition. Therefore, the greater the severity the greater the need of health care use.

The Ghana free maternal healthcare policy under the National Health Insurance Scheme (NHIS) offers low-risk pregnancy care by consultants and other skilled health personnel [23]. A key component of maternal care services in Ghana is the Focused Antenatal Care (FANC); a concept of the World Health Organisation, which was introduced in 2002. The major reasons for the introduction of the FANC is to woefully reduce maternal mortality rate and to encourage facility delivery, improve access, quality and continuity of ANC to pregnant women. However, some pregnant women still use the services of Traditional Birth Attendants (TBAs) with varied reasons $[6,7,15]$. This study, therefore, seeks to explore 
the knowledge and experiences on choice of place of delivery and postnatal care among reproductive women in urban Ghana.

\section{Methodology}

This qualitative study was conducted between 15th June and 15th October, 2015 in the Kwabre East Municipality of Ghana. The study questions 'why' some women still use the services of TBAs after the free maternal delivery services was mainstreamed in the healthcare system of Ghana. The case study design was used since the research question focusses on contemporary phenomenon and there was no control over behavioural events among study parameters $[24,25]$.

The study population was sought from the municipal health information management system software of the Ghana health services [26]. To discover the dynamics, which stimulate the knowledge and perceptions of factors influencing choice of place of delivery, two focus groups were conducted in the research enquiry. One comprised 8 women who had just delivered prior to the study with 2 nurses and 2 midwives. The other group had 8 mothers receiving postnatal care with 2 nurses and 2 midwives, in addition to an in-depth interview with the Municipal Health Nurse. Finally, informed consent was obtained from all study participants prior to their involvement.

\section{Data Analysis}

The study adopted thematic analysis using "exact" words by participants since this technique helps to categorise, deduce and account for themes in one's dataset [27]. This helps portray the interpretations, beliefs, experiences, and observations of respondents in relation to the epistemological positions of a research enquiry [27]. Again, the study employed manifest coding in its transcription to develop some deeper appreciation of contents through "thick description", to identify themes, stay flexible and openminded $[28,29]$. After coding was done, themes and analysis of transcripts were serialised, shared and discussed as prescribed by authorities $[27,29,30]$.

\section{Results}

This paper sought to explore the knowledge, perceptions, views and opinions influencing the choice of place of delivery with postnatal care among women in urban Ghana after the introduction of the FANC and the free health facility delivery, major components of the free maternal healthcare policy. 2 out of 16 mothers delivered home assisted TBA's and Table 1 below outlines the details of the study findings.

\section{Themes}

The themes acknowledged by the study, are presented and supported by Table 1 .

\section{Theme 1: knowledge on place of delivery}


Study participants shared and described their knowledge on the choice of place of delivery. The study revealed the importance of the intense education given to pregnant women alongside focused ANC. Most participants delivered in facilities with the motive to averting pregnancy and delivery complications. Some study participants shared their views as follows:

"...this is my fourth child and all were delivered here since the Nurse said my babies will be strong and fine." (A recently delivered mother from Antoa, FG2)

"The nurses told me that facility delivery is the safest and I should use it anytime I become pregnant." (A pregnant woman from Mamponteng, FG1)

However, a participant who used home delivery with assistance from TBAs shared her experience as:

"You know...please, for me erh, I believe in my local people that they are good ok, that is why I always want to deliver at home. You see, errh I have four children home...they (TBAs) advised me to have the scan and do some test and that is why I came here." (A recently delivered mother from Sakora Wonoo, FG2)

\section{Theme 2: Attitude of caregivers}

Most participants declared that attitude of caregivers (Doctors, Nurses, Midwives, laboratory technicians among others) influenced their use of facility delivery and other health care services. Hence, the study confirmed mixed feelings on the attitude of caregivers. A recently delivered woman recounted the experience below.

"... Me for instance, I like them because they chat and smile to me anytime I come here even before my labour. I think this is why more people want to come here." (Recently delivered woman from Asonomaso facility, FG1)

\section{Theme 3: Knowledge on postnatal care}

Some study participants noted that the postnatal care services are important to prevent complications after delivery and ensure maximum care for mother and baby. Comprehensive tests including HIV and hepatitis B are conducted on newborn babies, with uterus checking and BP conducted on mothers. A participant narrated the experience below:

"They checked for my blood pressure and did hepatitis B and HIV test. It is good for me I now know all those things" (Recently delivered woman from Asonomaso facility, FG1)

A revealing experience of the current study indicates that women who use home delivery go for the services of caregivers in health facilities under postnatal care. The municipal health nurse shared her experience below:

"As I told you earlier, ehmm... what we as the Municipal health directorate do is that, mothers and their newborn babies are always put under intensive care for at least six hours to make sure their conditions 


\section{Theme 4: satisfaction on place of delivery}

Satisfaction to place of delivery was at variance among respondents. Most participants were satisfied with facility delivery and wished to recommend facility delivery and services to others.

"It is my in-law who recommended I come here and I am satisfied with their services. I would also recommend this hospital to anyone that this place is good." (A pregnant woman from Asonomaso, FG1)

Notwithstanding, a participant from Antoa health facility shared a different view below:

"Yes, yes, due to family support, hmmm, this is my third pregnancy and I always deliver with the help of the TBA although my family always advised me to come for ANC and this is why I am here." (A pregnant woman from Antoa facility, FG2)

\section{Discussion}

The study was conducted to explore the knowledge and sources of information on mothers' place of delivery and postnatal care among reproductive women in urban Ghana. Study themes are discussed under the guidance of Andersen's healthcare utilisation model of health seeking behaviours with predisposing, enabling and need factors.

\section{Need factors}

The knowledge on the need for best delivery care is significant to influence women's choice of place of delivery [22]. 14 out of the 16 participants preferred facility delivery since that is where best care is assessed. Active facility care delivery involves the coordination of all stakeholders (eg healthcare system, government, NGOs, family and social support) towards the broader healthcare system. Generally, study findings indicated that the knowledge on the need to receive best care and actual care by pregnant women influenced their choice of place of facility delivery. The findings of this study corroborate previous studies including Nepal [11], Ghana [12], Cameroun [14], Ethiopia [31], and Zimbabwe [32]. Study findings recommend that health policies, which protect patients, should be adopted alongside more user-friendly approaches and methods that are able to attract pregnant women who use home delivery be implemented.

\section{Predisposing factors}

The care rendered to women and their babies is relevant to influence the use of facility delivery. The current findings revealed that comprehensive care is given to both mother and baby soon after delivery in addition to focused ANC. The postnatal care services include checking of BP, HIV test, hepatitis B test and vitamin A supplements in addition to uterus checking within 24 hours after delivery. Again, to ensure maximum care of newly born babies, oral polio drop, BCG injection against TB, cord test, eye test are undertaken in addition to the taking of birth weight of all newborn babies. Study findings revealed that 
these postnatal care services are offered to women who use home delivery. The findings of the current study is in consistent with the available studies in developing countries $[9,15,16]$. It is recommended that awareness creation on the use of facility delivery should be intensified.

\section{Enabling factors}

The study revealed mixed opinions among women's level of satisfaction on both prenatal and postnatal care. The attitude of caregivers is revealed by the study findings to have a significant influence on women's choice of place of delivery $[6,7,10,11]$. The study findings recommend institutions and individuals whose primary purpose is to improve health such as the Information Services Department (ISD) and the National Commission for Civic Education (NCCE) to intensify campaigns on maternal health-care use.

\section{Conclusion}

The current study sought to explore how widely facility delivery and postnatal care have been either accepted rejected among reproductive women in urban Ghana after the introduction of the FANC intervention. Study findings suggest that enabling factors, being human-induced aspects of care act as predictors to health care satisfaction. Consequently, these factors act as forces that facilitate or impede individual, joint, or ecological alteration based on their degree of availability.

Service improvements, which address aspects of care, are likely to have an impact on health seeking behaviour and utilisation. Though minimal, this study revealed that both prenatal and post natal services are handled by TBAs. Findings recommend that the municipal health directorate adopt more user-friendly approaches and interventions to attract mothers who use home delivery and retain those who deliver in facilities. There is also the need to accept and advance interventions that seek to promote broader health systems, since they permeate into both vertical and horizontal inclinations of societies. Thus, institutions, organisations and people whose primary purpose is to improve maternal health care are to be promoted.

\section{Limitation}

The current study was limited to women who have had experience in birth delivery and were either, receiving prenatal, or postnatal care, without considering perceptions of families and social structure, and the wider healthcare system. The knowledge and experiences of past deliveries could probably have influenced their responses in the focus groups and could affect the trustworthiness and of study results. Likewise, the study purposively selected 4 women receiving prenatal care, 4 women receiving postnatal care, 4 nurses, 4 midwives from four facilities and a public health nurse and this could raise questions on the reflexivity of study outcomes. Nevertheless, the study adopted several strategies outlined in previous literature for ensuring scientific scrutiny in rigorous qualitative method of enquiry to ensure credibility, dependability and conformability $[24,25,27,28,29,30,31]$.

\section{Abbreviations}


Antenatal Care ANC

Focus group FG

Focused Antenatal Care FANC

Kwabre East Health Directorate KEHD

Kwame Nkrumah University of Science and Technology KNUST

Information Services Department ISD

National Commission for Civic Education NCCE

National Health Insurance Scheme NHIS

Traditional Birth Attendants TBAs

Non-Governmental Organisation NGO

\section{Declarations}

\section{Ethics approval and consent to participate}

Ethical clearance for this study was sought for, and the Committee on Human Research and Publication Ethics (CHRPE) with reference number CHRPE/AP/407/15 of the Komfo Anokye Teaching Hospital (KATH) and Kwame Nkrumah University of Science and Technology (KNUST) gave a written approval on 10 December 2015. All participants were above 16 years.

\section{Consent for publication}

Not Applicable

\section{Availability of data and material}

All data supporting these findings are available upon request

\section{Competing interests}

The authors declare that they have no competing interests.

\section{Funding}

There was no funding for this study

\section{Authors' Contributions}


AJA is the Principal Investigator of the study and participated in its conception and design. AJA carried out the literature review and drafted the entire manuscript. OAA and AR contributed in the conception and design of the study and closely reviewed the analysis and manuscript. SD and AR participated in revising and finalising the manuscript. All authors read and approved the final manuscript especially in the coding stage.

\section{Acknowledgments}

The authors are grateful to the municipal health nurse, facility nurses and midwives in selected facilities. They are also grateful to all the study participants for their support during the data collection. Lastly, they would like to thank the Kwabre East Municipal Health Directorate for both personnel and logistic support.

\section{References}

1. Fotso JC, Ezeh AC, Essendi H. Maternal health in resource-poor urban settings: how does women's autonomy influence the utilisation of obstetric care services?. Reproductive Health. 2009 Dec: 6(1):9.

2. Akowuah JA, Agyei-Baffour P, Asibey BO. A Qualitative Study on the Pathways to Evidence-Based Antenatal Care in Periurban Ghana. Obstetrics and gynecology international. 2018;2018.

3. Ronsmans C, Graham WJ, Lancet Maternal Survival Series steering group. Maternal mortality: who, when, where, and why. The lancet. 2006 Sep 30;368(9542):1189-200.

4. Mulogo EM, Witte K, Bajunirwe F, Nabukera SK, Muchunguzi C, Batwala VK, Bagenda F, Farr C, Barry S. Birth plans and health facility based delivery in rural Uganda. East African medical journal. 2006 Mar 1;83(3):74.

5. Lozano R, Wang H, Foreman KJ, Rajaratnam JK, Naghavi M, Marcus JR, Dwyer-Lindgren L, Lofgren KT, Phillips D, Atkinson C, Lopez AD. Progress towards Millennium Development Goals 4 and 5 on maternal and child mortality: an updated systematic analysis. The Lancet. 2011 Sep 24;378(9797):1139-65.

6. Kruk ME, Paczkowski M, Mbaruku G, de Pinho H, Galea S. Women's preferences for place of delivery in rural Tanzania: a population-based discrete choice experiment. American journal of public health. 2009 Sep: 99(9):1666-72.

7. Titaley CR, Hunter CL, Dibley MJ, Heywood P. Why do some women still prefer traditional birth attendants and home delivery? a qualitative study on delivery care services in West Java Province, Indonesia. BMC pregnancy and childbirth. 2010 Dec: 10(1):43.

8. Wilcox D. The Guide to Effective Participation. 2003. http://www.partnerships.org.uk/guide/index.htm

9. Wang W, Alva S, Wang S, Fort A. Levels and trends in the use of maternal health services in developing countries. DHS Comparative Reports No. 26. ICF Macro: Calverton, Maryland; 2011.

10. Lwelamira J, Safari J. Choice of place for childbirth: prevalence and determinants of health facility delivery among women in Bahi District, Central Tanzania. Asian Journal of Medical Sciences. 2012 
May;4(3):105-12.

11. Karkee R, Binns CW, Lee AH. Determinants of facility delivery after implementation of safer mother programme in Nepal: a prospective cohort study. BMC pregnancy and childbirth. 2013 Dec: 13(1):193.

12. Moyer CA, Adongo PB, Aborigo RA, Hodgson A, Engmann CM. They treat you like you are not a human being: maltreatment during labour and delivery in rural northern Ghana. Midwifery. 2014 Feb $1 ; 30(2): 262-8$.

13. Kruk ME, Kujawski S, Mbaruku G, Ramsey K, Moyo W, Freedman LP. Disrespectful and abusive treatment during facility delivery in Tanzania: a facility and community survey. Health Policy and Planning. 2014 Sep 22;33(1):e26-33.

14. Annette CS, Wung BA, Ivo KK, Atanga SN, Fon NP. Facility-Based Delivery Service Utilisation among Women of Childbearing Age in Nguti Health District, Cameroon: Prevalence and Predictors. Gynecol Obstet (Sunnyvale). 2016; 6(416):2161-0932.

15. D'Ambruoso L, Abbey M, Hussein J. Please understand when I cry out in pain: women's accounts of maternity services during labour and delivery in Ghana. BMC public health. 2005 Dec: 5(1):140.

16. Gabrysch S, Campbell OM. Still too far to walk: literature review of the determinants of delivery service use. BMC pregnancy and childbirth. 2009 Dec;9(1):34.

17. Bowser D, Hill K. Exploring evidence for disrespect and abuse in facility-based childbirth. Boston: USAID-TRAction Project, Harvard School of Public Health. 2010 Sep 20.

18. Kruk ME, Kujawski S, Mbaruku G, Ramsey K, Moyo W, Freedman LP. Disrespectful and abusive treatment during facility delivery in Tanzania: a facility and community survey. Health Policy and Planning. 2014 Sep 22;33(1):e26-33.

19. Janz NK, Becker MH. The health belief model: A decade later. Health education quarterly. 1984 Mar;11(1):1-47.

20. Prochaska JO, Redding CA, Evers KE. The trans theoretical model and stages of change. 2008: 39, pp. 97-121

21. Ajzen I. The theory of planned behaviour. Organisation Behaviour and Human Decision Processes. 1991: 50 (2), 179-211.

22. Andersen, M. R. (1995). Revisiting the Behavioral Model and Access to Medical Care: Does It Matter? University of California, Los Angeles. Journal of Health and Social Behavior, Vol. 36 (March): 1-10.

23. Ghana Ministry of Health (GMoH, 2007): Annual report 2007. Ghana: Accra; 2007.

24. De Vaus DA, de Vaus D. Research design in social research. Sage; 2001 Feb 1.

25. Bowling A. Research methods in health: investigating health and health services. McGraw-Hill Education (UK); 2014 Jul 1.

26. Kwabre East Health Directorate. Analyses of Maternal Health Delivery. Kwabre East District Profile, 2013, KEHD, Kwabre District, Ghana. 2015. Accessed 21 Aug 2015 http://www.ghsdhims.org/dhims/dhis-web-reporting/ 
27. Braun V, Clarke V. Using thematic analysis in psychology. Qualitative research in psychology. 2006 Jan 1: 3(2):77-101.

28. Davies MB, Hughes N. Doing a successful research project: Using qualitative or quantitative methods. Macmillan International Higher Education; 2014 Mar 11.

29. Fereday J, Muir-Cochrane E. Demonstrating rigour using thematic analysis: A hybrid approach of inductive and deductive coding and theme development. International journal of qualitative methods. 2006 Mar: 5(1):80-92

30. Creswell, JW. Research design: qualitative, quantitative, and mixed methods approaches. Sage Publications. 2009.

31. Mekonnen, Y, Mekonnen, A. Utilisation of Maternal Health Care Services in Ethiopia. ORC Macro, Calverton, Maryland, USA. Utilisation of maternal health care services in Ethiopia. 2002.

32. Nunu WN, Ndlovu V, Maviza A, Moyo M, Dube O. Factors associated with home births in a selected ward in Mberengwa District, Zimbabwe. Midwifery. 2019 Jan 1;68:15-22.

\section{Tables}

Due to technical limitations, table 1 is only available as a download in the Supplemental Files section.

\section{Supplementary Files}

This is a list of supplementary files associated with this preprint. Click to download.

- Table1.jpg

- Table1a.jpg 